\title{
Quantitative Analysis by High-Performance Liquid Chromatography Atmospheric Pressure Chemical Ionization Mass Spectrometry: The Determination of the Renin Inhibitor CP-80,794 in Human Serum
}

\author{
Hassan Fouda, Mark Nocerini, Richard Schneider, and Caroline Gedutis \\ Drug Metabolism Department, Central Research Division, Pfizer, Inc., Groton, Connecticut, USA
}

\begin{abstract}
A specific method was developed for the quantitative determination of the renin inhibitor CP-80,794. Serum extracts containing the drug and an internal standard were injected into a standard reverse-phase high-performance liquid chromatography (HPLC) column. The mobile phase, methanol/water $(8 / 2)$, flowed at $1 \mathrm{~mL} / \mathrm{min}$ through the column and then via a heated nebulizer interface into a corona discharge atmospheric pressure chemical ionization source. The assay minimum limit of quantification was $50 \mathrm{pg} / \mathrm{mL}$. It exhibits satisfactory accuracy and precision over the range $50 \mathrm{pg} / \mathrm{mL}$ to $10 \mathrm{ng} / \mathrm{mL}$. A minor modification of the HPLC mobile phase was necessary to attain extremely low detection limits. The addition of a structural analogue contributed to enhancing the precision of the assay. ( $\mathrm{Am}$ Soc Mass Spectrom 1991, 2, 164-167)
\end{abstract}

$\mathrm{M}$ uch of the current excitement about highperformance liquid chromatography (HPLC) atmospheric pressure mass spectrometry (APMS) is due to the generation of multiply charged ions by electrospray $[1,2]$, which extends mass spectrometry to peptides and other large molecules $[1,3]$. Other approaches to interfacing HPLC and APMS have been partially overlooked. The heated nebulizer interface developed by Thomson [4] permitted gasphase atmospheric pressure chemical ionization (APCI) of materials eluting from standard HPLC columns. In our laboratory, the interface was applied to the analysis of several drugs and has resulted in detection limits and chromatographic fidelities approaching and sometimes exceeding those possible by gas chromatography mass spectrometry (GC/MS).

The modified peptide CP-80,794 (Figure 1, I) inhibits serum renin of various species and promises to be an efficacious orally active drug for the management of hypertension. Its in vitro inhibitory potency against human renin $\left(\mathrm{IC}_{50}=0.7 \mathrm{nM}\right.$ ) suggests pharmacological action at concentrations below $200 \mathrm{pg} / \mathrm{mL}$ [5]. A specific method for trace-level quantification of CP-80,794 in human serum was desired to investigate

Address reprint requests to Hassan Fouda, Drug Metabolism Department, Central Research Division. Pfizer, Inc., Groton, CT 06340. the drug's pharmacokinetics and pharmacodynamics in human subjects.

This article describes an assay employing the heated nebulizer interface for the quantitative determination of CP-80,794 by HPLC/APCI. Concentrations as low as $50 \mathrm{pg} / \mathrm{mL}$ of serum have been determined by selected ion monitoring.

\section{Experimental}

\section{Serum Extraction}

A 1-mL aliquot of human serum was placed in a silylated disposable culture tube containing $50 \mathrm{ng}$ of the carrier (Figure 1, III) in $100 \mu \mathrm{L}$ of methanol. To this was added $1 \mathrm{ng}$ of internal standard (Figure 1, II), and the sample was vortexed. The serum was made basic with $100 \mu \mathrm{L}$ of $1 \mathrm{~N} \mathrm{NaOH}$, vortexed, and extracted with $5 \mathrm{~mL}$ of $n$-butyl chloride for $10 \mathrm{~min}$ by using a reciprocating shaker. Following centrifugation for $5 \mathrm{~min}$, the aqueous layer was frozen in a dry ice/isopropyl alcohol bath. The organic layer was decanted into a silylated conical centrifuge tube containing $2 \mathrm{~mL}$ of acetonitrile, and the extract was evaporated to dryness in a vortex evaporator (block temp = $37^{\circ} \mathrm{C}$ ). An additional $1 \mathrm{~mL}$ of acetonitrile was added to the dried extract, vortexed, and the drying process 


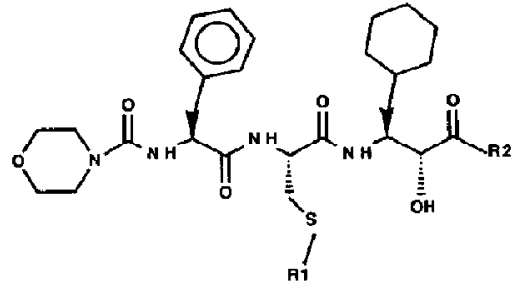

$\underline{R_{1}} \quad \underline{R_{2}}$

Molecular Wt.

I. Analyte: CP-80,794

$\mathrm{CH}_{3}$

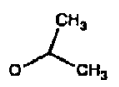

820

II. Internal Std: CP-88,587 $\mathrm{C}_{2} \mathrm{H}_{3}$

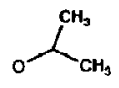

634

III. Carrier: CP-81,489

$\mathrm{CH}_{7} \quad \mathrm{NH}-\mathrm{CH}_{3}$

591

Figure 1. Structure of the subject compound and analogues used in the assay procedure.

was repeated. The dried residue was reconstituted in $60 \mu \mathrm{L}$ of methanol, followed by the addition of $40 \mu \mathrm{L}$ of water. Injections of $80 \mu \mathrm{L}$ were made onto the HPLC/MS system.

\section{Assay Calibration}

Human serum was fortified with CP-80,794 at 11 concentrations ( 6 replicates per concentration) ranging from 0.05 to $10 \mathrm{ng} / \mathrm{mL}$. Two standard curves were constructed to compare CP-80,794 concentrations vs. the peak height ratios of the drug over the internal standard. One curve was based on concentrations ranging from 0.1 to $10 \mathrm{ng} / \mathrm{mL}$. To accommodate samples containing less than $0.1 \mathrm{ng} / \mathrm{mL}$, a second curve was based on concentrations ranging from 0.05 to 1.0 $\mathrm{ng} / \mathrm{mL}$. The peak height data generated by the mass spectrometry data acquisition system were adjusted to reflect true electronic zero for a sample blank. This adjustment was arrived at by randomly measuring ion intensities of drug and internal standard in blank areas of each chromatogram and calculating mean values from those random measurements. The mean values were then subtracted from the acquired peak height data, thereby performing a background-subtracted quantitation routine.

Serum blanks and an 11-point standard curve (two samples per concentration) were run with each set of unknown samples. Data from linear regression analysis of each curve were used to calculate concentrations of the unknown samples by using the equation $y=$ $m x+b$. The high curve was used for all samples. Samples shown to contain concentrations less than $0.1 \mathrm{ng} / \mathrm{mL}$ were recalculated by using the low curve.

\section{Analysis}

The mobile phase was prepared by mixing HPLCgrade methanol and water $(8 / 2)$ and degassing through a $0.7-\mu \mathrm{m}$ glass fiber filter. The analytical column was a WATERS (Milford, MA) C-18 Nova-Pak $(3.9 \times 150 \mathrm{~mm})$, preceded by an SSI (State College, PA) precolumn stainless steel filter $(0.5 \mu \mathrm{m})$. An LDC (Riviera Beach, FL) Constametric 3000 pump was used, and a flow rate of $1 \mathrm{~mL} / \mathrm{min}$ was established. A Perkin-Elmer (Norwalk, CT) ISS-100 autosampler injected $80-\mu \mathrm{L}$ sample aliquots onto the column at $4-\mathrm{min}$ intervals. The column effluent was interfaced to the heated nebulizer probe of the mass spectrometer. Nonretained peaks, drug, and internal standard had elution times of 1.0, 3.1, and $3.4 \mathrm{~min}$, respectively, in the system described here.

The analysis was performed on a SCIEX (Thornhill, Canada) API III HPLC/MS system. The effluent from the HPLC column flowed into the atmospheric pressure ionization source via a heated nebulizer interface (nebulizer probe temp $=500^{\circ} \mathrm{C}$ ). The nitrogen nebulizing gas pressure of the interface was fixed at 95 psi, and auxiliary flow was set at $3.4 \mathrm{~L} / \mathrm{min}$. Prior to each period of analysis, instrumental performance was determined by injecting $10 \mathrm{pg}$ (flow injection; no column) of CP-80,794. A response $\geq 3$ times the mean background signal indicated adequate performance. Gas-phase chemical ionization was effected by a Corona discharge needle $(-2.5 \mu \mathrm{A})$. Negative ions formed in the source were sampled into the quadrupole mass filter via a $0.0045^{\prime \prime}$ pinhole aperture. The mass spectrometer was adjusted to selectively monitor drug anions $[\mathrm{M}-\mathrm{H}]^{-}$at $m / z=619$, and internal standard anions $[\mathrm{M}-\mathrm{H}]^{-}$at $m / z=633$, each ion at a dwell time of $500 \mathrm{msec}$. The nitrogen curtain gas was adjusted to a constant flow rate of 1.2 $\mathbf{L} / \mathbf{m i n}$. Voltage parameters of the quadrupoles and Brubaker lenses used during sample analysis were as follows: $\mathrm{OR}=-\mathbf{3 3} \mathrm{V}, \mathrm{RO}=-\mathbf{3 0} \mathrm{V}, \mathrm{R} 1=-26 \mathrm{~V}$, $\mathbf{L 7}=0 \mathrm{~V}, \mathrm{R} 2=0 \mathrm{~V}, \mathrm{R} 3-0 \mathrm{~V}, \mathrm{~L} 9=-30 \mathrm{~V}$. Voltages for the Faraday plate and the multiplier were $-160 \mathrm{~V}$ and $+5000 \mathrm{~V}$, respectively. The channel electron multiplier was operated in a pulsc-counting mode, and was capable of recording $4 \times 10^{6}$ counts $/ \mathrm{s}$. The power supplies were adjusted so that unit mass resolution was achieved (RE - 120).

\section{Results and Discussion}

The potent pharmacological activity of the renin inhibitor CP-80,794 necessitated its quantitative determination in the low $\mathrm{pg} / \mathrm{mI}$. range. The low volatility and thermal instability of this modified tripeptide precluded the use of GC/MS for its analysis. In addition, the drug lacks a significant chromophore, electrophore, or fluorophore to permit its trace-level determination by standard HPLC methods. Hydrolysis of the bond between the phenylalanine and S-methyl cysteine residues of CP-80,794 followed by fluorescence derivatization of the resulting amine-containing 
fragment did not provide the sensitivity required for detection of therapeutic concentrations of CP-80,794.

Although thermospray HPLC/MS has been used for low-level quantitative determination of certain compounds, the technique is known to be compound-specific [6]. For most compounds, its practical detection limits are 10 to 50 times higher than obtainable by GC/MS [7]. For CP-80,794, the minimum limit of detection by thermospray was $50 \mathrm{ng}$.

The commercial availability of a mass spectrometer designed specifically for atmospheric pressure ionization (SCIEX) provides another option for on-line HPLC/MS. The instrument supports two approaches for HPLC/MS interfacing: heated pneumatic nebulization [4] and pneumatically assisted electrospray [2]. The two approaches complement each other; together they are applicable to essentially all classes of compounds. In our laboratory they have outperformed thermospray in the analysis of many drugs and metabolites.

The heated nebulizer interface permits gas-phase APCI of analytes eluting in the HPLC mobile phase [4]. The technique generates mild ionization conditions, and the internal energy of the ions is low. The rapid desolvation of the nebulized droplets minimizes fragmentation or thermal decomposition, and provides abundant molecular ions $[8,9]$. The outer jacket of the nebulizer probe is usually maintained at $350-500^{\circ} \mathrm{C}$ depending on the solvent composition and flow rates. However, the solvent and analyte molecules do not come in contact with this temperature. The vapor temperature was estimated to be $125-150^{\circ} \mathrm{C}$ [7]. Although the interface is compatible with various reverse-phase mobile-phase compositions and flow rates of up to $2 \mathrm{~mL} / \mathrm{min}$ [7], there are limitations to low-level detection with buffered mobile phases. A buffered mobile phase produces an erratic and nonreproducible baseline, significantly reducing signal-to-noise ratios. The relative intensity of the baseline noise correlates with the concentration of ammonium acetate in the mobile phase (Figure 2). The increased background noise appears to be due to the formation of buffer ion clusters, which can be declustered by increasing the dry nitrogen curtain gas flow rate or by increasing the voltage of the orifice plate. This, however, decreases the signal from the analyte. The background noise can sufficiently be reduced to detect CP-80,794 concentrations of $50 \mathrm{pg} / \mathrm{mL}$ only when the buffer components are eliminated from the mobile phase.

A structural analogue of $\mathrm{CP}-80,794$ served as an internal standard (Figure 1, II). A second structural analogue (III) was added to each sample to reduce adsorption losses during sample preparation and HPLC/MS analysis [10]. High concentrations of IIT enhanced extraction efficiency and the precision of the assay (Table 1), presumably due to carrier effects [11]. The results show that for those samples spiked with carrier, the extraction efficiency of the drug and the
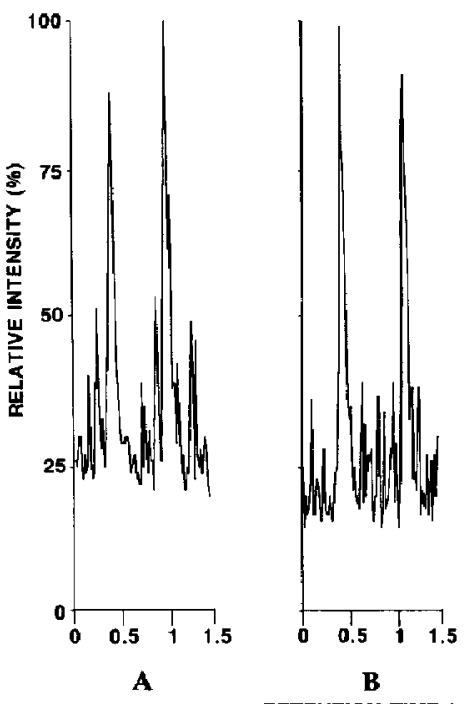

RETENTION TIME (min)

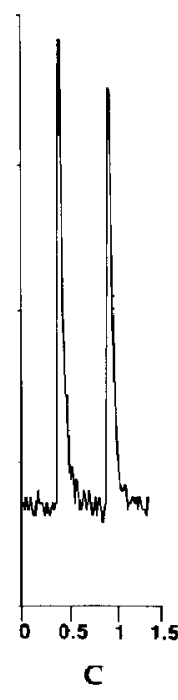

Figure 2. The effect of mobile-phase composition on signal-tonoise for duplicate $100-\mathrm{pg}$ injections of CP-80,794. (a) $10 \mathrm{mM}$ ammonium acetate:methanol, (b) $5 \mathrm{mM}$ ammonium acetate:methanol, (c) water:methanol.

Table 1. Effect of adding $50 \mathrm{ng} / \mathrm{mL}$ of the carrier CP-81,489 (III) to serum samples fortified with $\mathrm{CP}-80,794$ at $0.1 \mathrm{ng} / \mathrm{mL}$

\begin{tabular}{|c|c|c|c|}
\hline Sample \# & $\begin{array}{l}\text { Drug } \\
\text { pk ht }\end{array}$ & $\begin{array}{c}\text { IS } \\
\mathrm{pk} h \mathrm{t}\end{array}$ & $\begin{array}{l}\text { Adjusted } D / I S \\
\text { ratios }\end{array}$ \\
\hline \multicolumn{4}{|c|}{ Without Carrier: } \\
\hline 1 & 4420 & 10080 & 0.140 \\
\hline 2 & 4400 & 7660 & 0.205 \\
\hline 3 & 4140 & 5960 & 0.243 \\
\hline 4 & 4560 & 6020 & 0.371 \\
\hline 5 & 3900 & 6320 & 0.192 \\
\hline 6 & 3880 & 6660 & 0.180 \\
\hline 7 & 4000 & 6740 & 0.197 \\
\hline 8 & 3860 & 6560 & 0.182 \\
\hline 9 & 3840 & 6000 & 0.211 \\
\hline 10 & 3640 & 5960 & 0.229 \\
\hline Mean & 4064 & 6796 & 0.210 \\
\hline Std. Dev. & 303 & 1268 & 0.060 \\
\hline C.V. ${ }^{\mathrm{a}}$ & 7.5 & 18.7 & 29 \\
\hline \multicolumn{4}{|c|}{ With Carrier: } \\
\hline 11 & 5100 & 8300 & 0.127 \\
\hline 12 & 5560 & 9740 & 0.186 \\
\hline 13 & 4900 & 7160 & 0.162 \\
\hline 14 & 4940 & 7660 & 0.178 \\
\hline 15 & 5180 & 10440 & 0.167 \\
\hline 16 & 5080 & 8500 & 0.099 \\
\hline 17 & 4800 & 7920 & 0.175 \\
\hline 18 & 4780 & 8340 & 0.181 \\
\hline 19 & 4920 & 10200 & 0.159 \\
\hline 20 & 4720 & 7820 & 0.179 \\
\hline Mean & 4998 & 8608 & 0.160 \\
\hline Std. Dev. & 247 & 1127 & 0.030 \\
\hline C.V. ${ }^{a}$ & 4.9 & 13.1 & 17 \\
\hline
\end{tabular}

\footnotetext{
a Coefficient of variation.
} 


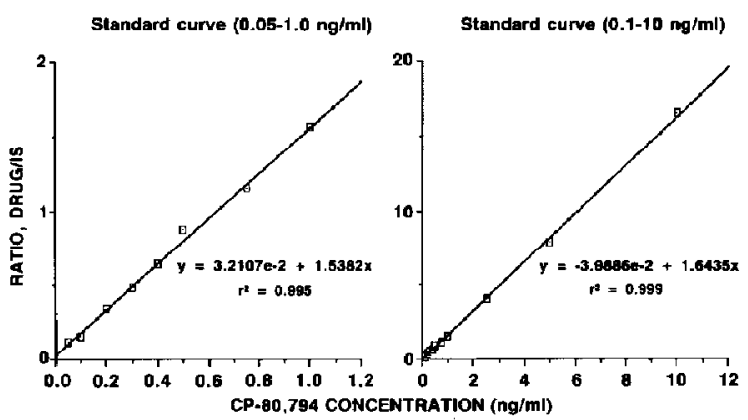

Figure 3. Standard curves of the CP-80,794 assay for concentrations ranging from 0.05 to $10 \mathrm{ng} / \mathrm{mL}$.

internal standard was improved by approximately $\mathbf{2 4 \%}$, and the assay precision was improved by approximately $35 \%$.

The linear dynamic range of the assay is quite narrow. For best accuracy, two standard curves (Figure 3) were required for concentrations ranging from 0.05 to $10 \mathrm{ng} / \mathrm{mL}$. The narrow dynamic range of the assay was also evident in other APCI or electrospray methods. We cannot at this time offer a satisfactory explanation of this phenomenon. Typically, the background level of APCI is high, and background subtraction routines were required for best linear regression analyses and smallest $y$-intercept.

The present assay permits the quantitation of $\mathrm{CP}$ 80,794 in serum over the range 0.05 to $10 \mathrm{ng} / \mathrm{mL}$ with satisfactory accuracy and precision (Table 2; Figure 4). Samples containing more than $10 \mathrm{ng} / \mathrm{mL}$ can be diluted with control serum before analysis. The assay has already been used to support several clinical studies. The mass spectrometer, which has been in continuous use for over one year, proved to be reliable and rugged. No significant downtime or mass marker drift was encountered. During the continuous introduction of biological samples, the signal for the analyte steadily decreases because of the buildup of a deposit on the corona discharge needle. Cleaning or replacing the

Table 2. Analysis of serum samples containing known amounts of CP-80,794; intra-assay parameters $(n=6)$

\begin{tabular}{cccc}
\hline $\begin{array}{c}\text { Fort. conc. } \\
\text { (ng/mL) }\end{array}$ & $\begin{array}{c}\text { Conc. found } \\
\text { (ng/mL) }\end{array}$ & \multicolumn{1}{c}{ C.V. $^{\mathrm{h}}$} & $\begin{array}{c}\% \\
\text { accuracy }\end{array}$ \\
\hline \hline 0.05 & 0.052 & 7.7 & 104 \\
0.10 & 0.119 & 10.1 & 119 \\
0.20 & 0.227 & 9.7 & 113 \\
0.30 & 0.313 & 6.4 & 104 \\
0.40 & 0.407 & 5.4 & 102 \\
0.50 & 0.556 & 7.7 & 111 \\
0.75 & 0.717 & 5.0 & 96 \\
1.00 & 1.034 & 5.8 & 103 \\
2.50 & 2.488 & 12.5 & 100 \\
5.00 & 4.820 & 6.7 & 96 \\
10.00 & 10.094 & 9.9 & 101 \\
\hline
\end{tabular}

a Fortified concentration.

${ }^{b}$ Coefficient of variation.

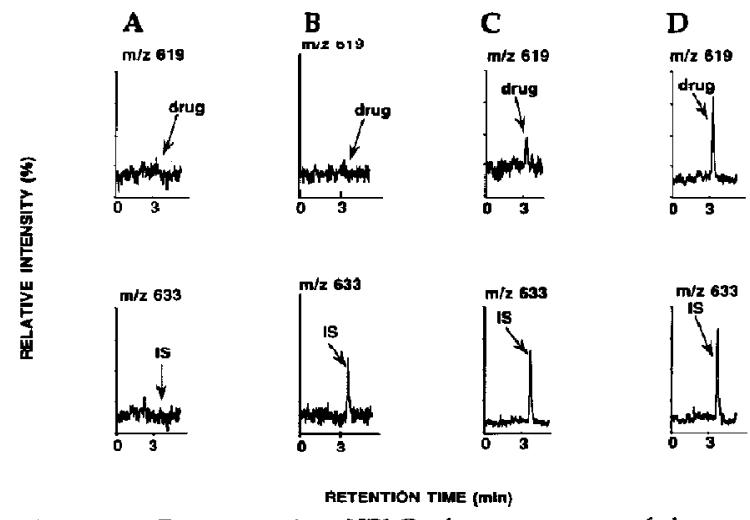

Figure 4. Representative HPLC chromatograms of human serum samples. Extracted ion currents for (a) Blark, (b) Blank + IS, (c) $0.1 \mathrm{ng} / \mathrm{mL}$, and (d) $0.5 \mathrm{ng} / \mathrm{mL}$.

needle, an operation requiring about one minute, regenerates the initial response. During the present assay, the needle was cleaned after every 50 serum samples.

\section{Summary}

The use of HPLC/APMS allowed the quantitative determination of the subject compound down to 50 $\mathrm{pg} / \mathrm{mL}$ of scrum. The assay has thus far been applied to the analysis of more than four thousand clinical samples.

\section{Acknowledgment}

The authors are grateful to Drs. T. Covey and B. Thomson of SCIEX for several helpful suggestions for the optimization of mass spectrometry parameters.

\section{References}

1. Fenn, J. B.; Mann, M.; Meng, C. K.; Wong, S. F.; Whitehouse, C. M. Science 1989, 246, 64.

2. Bruins, A. P.; Covey, T. R.; Henion, J. D. Anal. Chem. 1987 59, 2642.

3. Covey, T. R.; Bonner, R. F.; Shushan, B. I.; Henion, J. D. Rapid Commun. Mass Spectrom. 1988, 1, 249.

4. Thomson, B. A.; Danylewych, M. L. 31st Axtnual Conference on Mass Spectrometry and Allied Topics, Boston, 1983, p. 852.

5. Murphy, W. R.; Wester, R. T.; Hoover, D. J.; Holt, W. F.; Rosati, R. L.; Purcell, I. M.; MacAndrew, I. T.; Schelhorn, T. M.; Wilder, D. E.; Smith, A. H. In Amino Acids: Chemistry, Biology, and Medicine; Lubec, G., Rusenthal, G. A.; Eds.; ESCOM Science Publishers B. V., 1990; PP. 676-688.

6. Straub, K. M. Progress in Drug Metabolism 1988, 11, 267.

7. Covey, T. R,; Lee, E. D.; Bruins, A. P.; Henion, J. D. Anal. Chem, 1986, 58, 1451A.

8. Crowther, J. B.; Covey, T. R.; Silverstre, D.; Henion, J. D. LC Magazine 1985, 3, 240.

9. Covey, T. R.; Lee, E. D.; Henion, J. D. Anal. Chem. 1986, $58,2453$.

10. Self, R. Biomed. Mass Spectrom. 1978, 6, 315.

11. Lee, M. G.; Millard, B. J. Biomed. Mass Spectrom. 1975, 2, 78. 